\title{
RP-HPLC method development and validation for simultaneous estimation of Cilnidipine, Atenolol and Chlorthalidone
}

\author{
Vishal Singh Solanki, Ram Singh Bishnoi*, Raviraj Baghel, Deepti Jain, \\ School of Pharmaceutical Sciences, Rajiv Gandhi Proudyogiki Vishwavidyalaya, Bhopal Madhya Pradesh (India)-462033
}

\begin{abstract}
A simple precise and economical reverse phase high performance liquid chromatographic method has been developed and validated for the simultaneous estimation of Cilnidipine (CDP), Atenolol (ATL) and Chlorthalidone (CTD).The chromatographic separation was achieved by using Hypersil- keystone $\mathrm{C}_{18}(4.6 \times 250 \mathrm{~mm}, 5 \mu \mathrm{m})$ under isocratic conditions The mobile phase consisted of methanol and triple distilled water $(80 / 20, \mathrm{v} / \mathrm{v})$ having $\mathrm{pH} 7$ with a flow rate of $1.0 \mathrm{~mL} / \mathrm{min}$. The eluents were monitored at $225 \mathrm{~nm}$ for simultaneous measurement.The selected chromatographic conditions were found to effectively separate CDP (Rt: $3.25 \mathrm{~min}$ ), ATL (Rt: $5.366 \mathrm{~min}$ ) and CTD (Rt: $9.025 \mathrm{~min}$ ) having good resolution. The developed method was validated for linearity, accuracy, precision, LOD, LOQ, robustness and for system suitability parameters as per ICH guidelines. In this study, an excellent linearity was obtained with $\mathrm{r}^{2}=0.999, \mathrm{r}^{2}=0.999, \mathrm{r}^{2}=1$, for CDP, ATL and CTD respectively. The developed chromatographic method proved to be simple, precise, accurate, robust and reproducible Thus, this method would be employed for routine simultaneous quantification of CDP, ATL and CTD in bulk form or tablet dosage form.
\end{abstract}

Keywords: Cilnidipine, Atenolol and Chlorthalidone, RP-HPLC.

Article Info: Received 21 Oct 2018; Review Completed 27 Nov 2018; Accepted 28 Nov 2018; Available online 15 Dec 2018

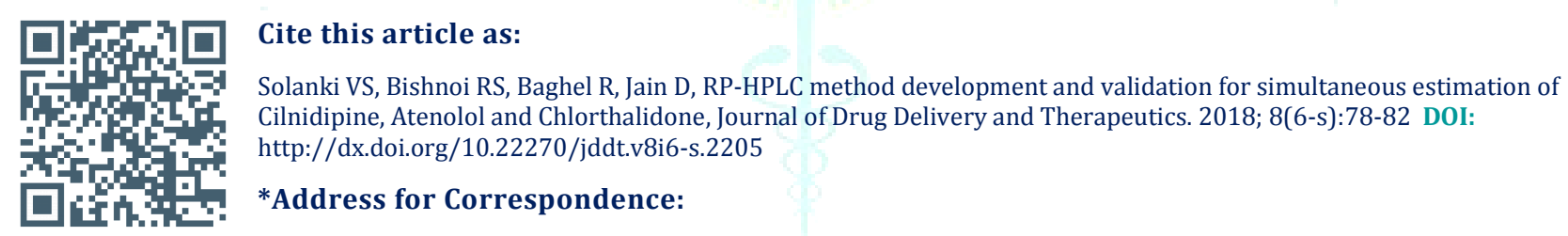

Ram Singh Bishnoi, School of Pharmaceutical Sciences, Rajiv Gandhi Proudyogiki Vishwavidyalaya, Bhopal Madhya Pradesh (India)-462033.

\section{INTRODUCTION}

Development of analytical method and validation are the continuous and inter-dependent task associated with the research and development, quality control and quality assurance area. Analytical procedures play important role in equivalence and risk assessment, management. It helps in establishment of acceptance criteria and stability of results. Validation should demonstrate that the analytical procedure is suitable for its intended use. Design of experiment is a important tool for the method characterization and validation. Analytical professionals should be comfortable to use it to optimize the analytical method. A good analytical method development and its validation can provide significant improvements in precision and a reduction of errors. It can help to avoid costly and time consuming exercises. ${ }^{1}$

Cilnidipine (CDP) 1,4-dihydro-2,6-dimethyl-4-(3nitrophenyl)-3,5-pyridinecarboxylic acid 2methoxyethyl(2e)-3-phenyl-propenyl ester (fig. 1). ${ }^{2}$ CDP is a novel and unique 1,4-dihydropyridine derivative calcium antagonist with potent inhibitory actions against not only L-type but also $\mathrm{N}$-type voltage dependent calcium channels. ${ }^{3}$ The N-type voltage-dependent calcium channel plays an important role in sympathetic neurotransmission and regulates the release of norepinephrine from sympathetic nerve endings ${ }^{4}$. It has been reported that once-daily administration of CDP resulted in a safe and more effective BP decrease in essential hypertension without excessive BP reduction or reflex tachycardia than similar administration than once-daily administration of nifedipine or nisoldipine.5,6<smiles>COCCOC(=O)C1=C(C)NC(C)=C(C(=O)OC/C=C/c2ccccc2)C1c1cccc([N+](=O)[O-])c1</smiles>

Figure 1: Structure of Cilnidipine

Atenolol (ATL), 4-[2-Hydroxy-3-[(1-methylethyl) amino] propoxy] phenylacetamide (fig.2) is a selective $\beta 1$ adrenoceptor antagonist applied in the treatment of numerous cardiovascular disorders such as hypertension and angina .The cardio selectivity of ATL is not absolute 
and at higher doses inhibits $\beta 2$-adrenergic receptors, resulting in bronchospasm. ATL is absorbed quickly but not completely by the gastrointestinal tract. After oral administration of ATL, approximately $50-60 \%$ of the dose is absorbed and the rest is excreted unchanged in the feces. ATL undergoes little or no metabolism and is eliminated primarily by renal excretion..$^{7-8}$<smiles>CC(C)NCC(O)COc1ccc(CC(N)=O)cc1</smiles>

Figure 2: Structure of Atenolol

Chlorthalidone (CTD) is a sulphamyl benzophenone derivative [2-chloro-5-(1-hydroxyl-3-oxo-2,3-dihydro-1Hisoindol-1-yl) benzene-1-sulfonamide] (Fig. 3).It is a diuretic agent used in the treatment of edema associated with congestive heart failure. ${ }^{9}$ CTD is also used in hypertension therapy. This sulphonzunide-like diuretic differs chemically from the thiazides by the nature of the heterocyclic ring, although its pharmacological action is indistinguishable from that of the thiazides. ${ }^{10}$<smiles>NS(=O)(=O)c1cc(C2(O)NC(=O)c3ccccc32)ccc1Cl</smiles>

Figure 3: Structure of Chlorthalidone

\section{MATERIALS AND METHODS}

\subsection{RP-HPLC method}

\subsubsection{Materials and reagents}

Cilnidipine from Laksh Fine Chem Pvt. Ltd Anand, Gujarat, India Atenolol and Chlorthalidone from Ipca laboratories Ratlam Madhya Pradesh India, were received as a gift sample. Methanol of HPLC grade from Qualigens fine chemicals, Mumbai, India. All the reagents and chemicals used were of analytical and HPLC grade. Water (HPLC grade) was obtained from Milli Q RO system.

\subsubsection{Instruments and Chromatographic Conditions}

Waters 600 Controller HPLC system was used for method development and validation. Data acquisition was performed on Data Ace HPLC software. The separation were achieved on $\mathrm{C}_{18}(250 \times 4.6 \mathrm{~mm}, 5 \mu \mathrm{m})$ column at ambient temperature and the eluent was monitored at 225 $\mathrm{nm}$ with flow rate of $1.0 \mathrm{~mL} / \mathrm{min}$ using UV detector. The mobile phase mixture of 80 parts Methanol \& 20 parts Water was filtered through nylon $0.22 \mu \mathrm{m}$ membrane filters and was degassed before use (30 min). A volume of $20 \mu \mathrm{L}$ of each sample was injected into column.

\subsubsection{Preparation of standard solution}

The standard stock solutions containing CDP $\quad(1000$ $\mu \mathrm{g} / \mathrm{mL})$, ATL $(1000 \mu \mathrm{g} / \mathrm{mL})$ and CTD $(600 \mu \mathrm{g} / \mathrm{mL})$ were prepared with methanol. The respective standard sub stock solutions containing CDP $(100 \mu \mathrm{g} / \mathrm{mL})$, ATL $(100 \mu \mathrm{g} / \mathrm{mL})$ and CTD $(60 \mu \mathrm{g} / \mathrm{mL})$ were prepared separately by dissolving with methanol. $1 \mathrm{~mL}$ aliquots from the standard stock solutions of CDP, ATL \& CTD were transferred to 10 $\mathrm{mL}$ calibrated volumetric flask and the volume was made up to the mark with the same solvent mixture to prepare a mixed standard preparation having a concentrations CDP $(10 \mu \mathrm{g} / \mathrm{mL})$, ATL $(10 \mu \mathrm{g} / \mathrm{mL})$ and CTD $(6 \mu \mathrm{g} / \mathrm{mL})$. Calibration curve solutions containing CDP $(10-50 \mu \mathrm{g} / \mathrm{mL})$, ATL $(10-50 \mu \mathrm{g} / \mathrm{mL})$ and CTD $(6-30 \mu \mathrm{g} / \mathrm{mL})$ were prepared by diluting the standard stock solution to the appropriate volume with the same diluent.

\subsection{Validation of the HPLC method}

\subsubsection{System suitability}

The developed method was validated according to ICH guidelines ${ }^{11}$. To check the system performance, the system suitability parameters were measured. System precision was determined on six replicate injections of standard preparations. Number of theoretical plates and asymmetry were measured ${ }^{12-13}$. The system suitability was assured by determining peak retention time, peak area, theoretical plates and tailing or asymmetry factor for CDP, ATL and CTD. The ideal values for system suitability are $\mathrm{CV}<1 \%$, asymmetry factor $<2$ and theoretical plates $>2000^{14}$. Six replicate samples were used for determining the system suitability.

\subsubsection{Linearity}

Calibration graphs were constructed by plotting peak area vs concentration of CDP, ATL and CTD and the regression equations were calculated. The calibration graphs were plotted over 5 different linear concentrations in the range of $10-50 \mu \mathrm{g} / \mathrm{mL}$ for CDP, $10-50 \mu \mathrm{g} / \mathrm{mL}$ for ATL and $6-36$ $\mu \mathrm{g} / \mathrm{mL}$ for CTD. All the solution were filtered through 0.22 $\mu \mathrm{m}$ membrane filter Aliquots $(20 \mu \mathrm{l})$ of each solution were injected under the operating chromatographic condition described above [Number of replicates $(n=6)]$. A calibration graph was plotted between the mean peak area Vs respective concentration and regression equation was derived.

\subsubsection{Accuracy}

Accuracy is the percent of analyte recovered by assay from a known added amount. For the measurement of accuracy data from nine determinations over three concentration levels covering the specified range were determined

\subsubsection{Precision}

Precision is the degree of repeatability of an analytical method under normal operational conditions. The precision of the assay was determined by repeatability (intra-day) and intermediate precision (inter-day) and reported as \% R.S.D. for a statistically significant number of replicate measurements. The intermediate precision was studied by comparing the assays on 3 different days and the results documented as standard deviation and $\%$ R.S.D ${ }^{15}$.

\subsubsection{LOD and $L O Q$}

The limit of detection (LOD) is defined as the lowest concentration of an analyte that an analytical process can reliably differentiate from background levels. The limit of quantification (LOQ) is defined as the lowest concentration of the standard curve that can be measured with acceptable accuracy, precision and variability (ICH guideline Q2B, 2005). The LOD and LOQ were calculated as

$$
\begin{aligned}
& L O D=3.3 \sigma / S \\
& L O D=10 \sigma / S
\end{aligned}
$$

Where $\sigma$ is the standard deviation of the lowest standard concentration and $S$ is the slope of the standard curve. 


\subsubsection{Robustness}

The robustness of the method was evaluated by assaying the test solutions after slight but deliberate changes in the analytical condition ns like flow rate $(+0.1 \mathrm{~mL} \mathrm{~min}-1)$, and mobile phase composition (2\%).

\section{RESULT AND DISCUSSION}

\subsection{System suitability}

In the present HPLC method, methanol and triple distilled water $(80 / 20, v / v)$ were used as mobile phase. In a preliminary separate analysis study of CDP, ATL and CTD with $\mathrm{C}_{18}$ column was successfully used; therefore, $\mathrm{C}_{18}$ was used simultaneous determination. The described chromatographic conditions resulted in CDP, ATL and CTD retention at about 3.25, 5.36 and 9.02 minutes, According to the USP, the HPLC method is considered suitable when the $\mathrm{CV}$ of peak area $<1 \%$, the tailing factor $<2$ and the theoretical plates $>2000$. The results of system suitability are shown in Table 1. All the measured parameters are within the recommended limits. Thus, our results suggested that the described method was suitable for the simultaneous determination of CDP, ATL and CTD. Moreover, the analyses of the analyte-containing samples exhibited well-differentiated peaks of the analytes at their respective retention times, even at the lower concentrations. No additional peak, interfering with the analyte-peaks, was seen in the chromatogram
Table 1: System suitability

\begin{tabular}{|l|l|l|l|}
\hline Parameter & CDP & ATL & CTD \\
\hline Peak area & 43127.94 & 36543.81 & 105615.71 \\
\hline Retention time & $3.25 \pm 0.06$ & $5.36 \pm 0.08$ & $9.02 \pm 0.08$ \\
\hline $\begin{array}{l}\text { Theoretical } \\
\text { plates }\end{array}$ & 4542 & 3653 & 2985 \\
\hline Tailing factor & $1.12 \pm 0.04$ & $1.18 \pm 0.06$ & $1.26 \pm 0.10$ \\
\hline Each value denotes the mean $\pm \bullet \% C V(n=6)$. \\
\hline
\end{tabular}

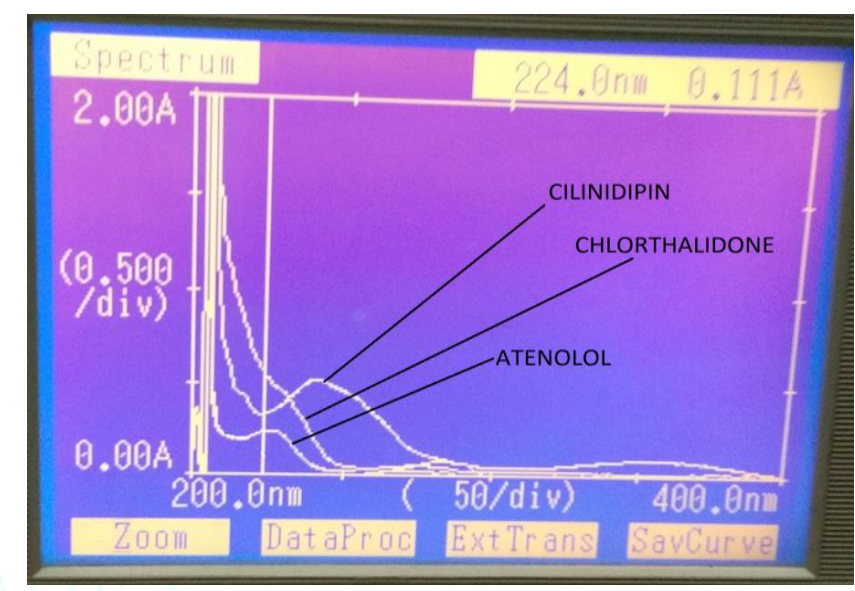

Figure 4: Overlay UV Spectra of CDP, ATL and CTD standard

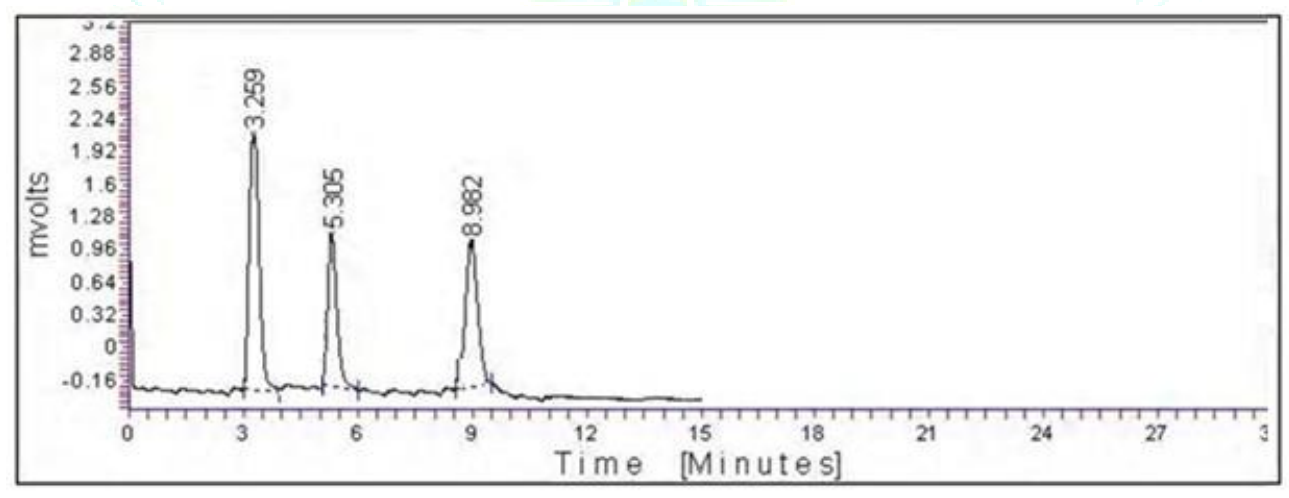

Figure 5: Chromatogram of CDP, ATL and CTD standard

\subsection{Linearity}

The linearity range for constructing the calibration curves for CDP, ATL and CTD were assessed by analysis of combined standard solution in range of $10-50 \mu \mathrm{g} / \mathrm{ml}, 10-50$ $\mu \mathrm{g} / \mathrm{ml}$ and $6-30 \mu \mathrm{g} / \mathrm{ml}$ respectively. The responses were linear throughout the range for all three analytes $\left(r^{2}=\right.$ $0.999, r^{2}=0.999$ and $r^{2}=1.00$, respectively).

The regression analysis is shown in table

Table 2: Regression analysis

\begin{tabular}{|l|c|c|c|}
\hline & CDP & ATL & CTD \\
\hline Slop & 1401 & 1220 & 3507 \\
\hline Intercept & 438.2 & 415.8 & 274.4 \\
\hline Correlation coefficient $\left(\mathrm{r}^{2}\right)$ & 0.999 & 0.999 & 1.00 \\
\hline \multicolumn{4}{|l|}{ Each value represents the mean \pm SD (n =6). } \\
\hline
\end{tabular}

The regression line equation for CDP, ATL and CTD are as following:

$$
\begin{array}{ll}
\text { For CDP } & y=1401 . x+438.2 \text { and } \\
\text { For ATL } & y=1220 . x-415.8 \text { and } \\
\text { For CTD } & y=3507 . x+274.4
\end{array}
$$

Table 3: Linearity data for CDP

\begin{tabular}{|c|c|c|}
\hline S. No. & Concentration & Area under curve \\
\hline 1 & 10 & 14233.14 \\
\hline 2 & 20 & 28538.94 \\
\hline 3 & 30 & 43127.94 \\
\hline 4 & 40 & 55929.99 \\
\hline 5 & 50 & 70625.85 \\
\hline
\end{tabular}




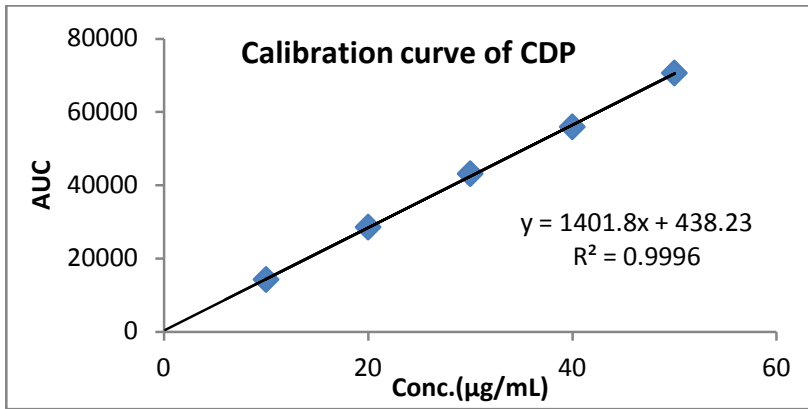

Figure 5: Calibration Graph of CDP

Table 4: Linearity data for ATL

\begin{tabular}{|c|c|c|}
\hline S. No. & Concentration & Area under curve \\
\hline 1 & 10 & 12087.33 \\
\hline 2 & 20 & 23368.58 \\
\hline 3 & 30 & 36543.81 \\
\hline 4 & 40 & 48478.81 \\
\hline 5 & 50 & 60577.31 \\
\hline
\end{tabular}

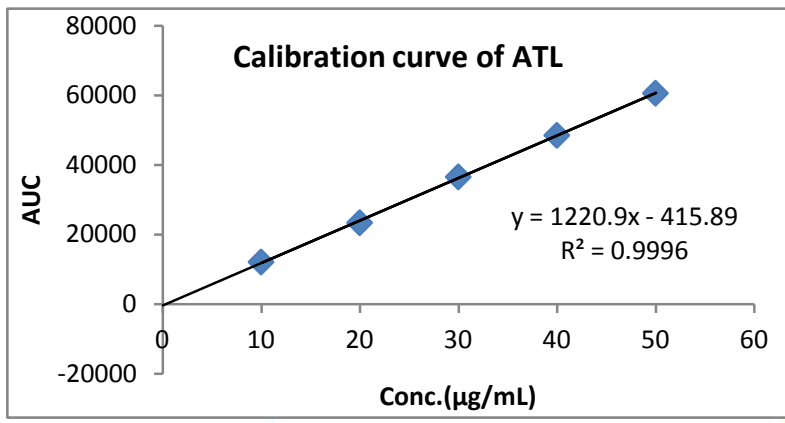

Figure 6: Calibration of ATL

Table 4: Linearity data for CTD

\begin{tabular}{|c|c|c|}
\hline S. No. & Concentration & Area under curve \\
\hline 1 & 6 & 21185.59 \\
\hline 2 & 12 & 42596.73 \\
\hline 3 & 18 & 63473.86 \\
\hline 4 & 24 & 84208.88 \\
\hline 5 & 30 & 105615.71 \\
\hline
\end{tabular}

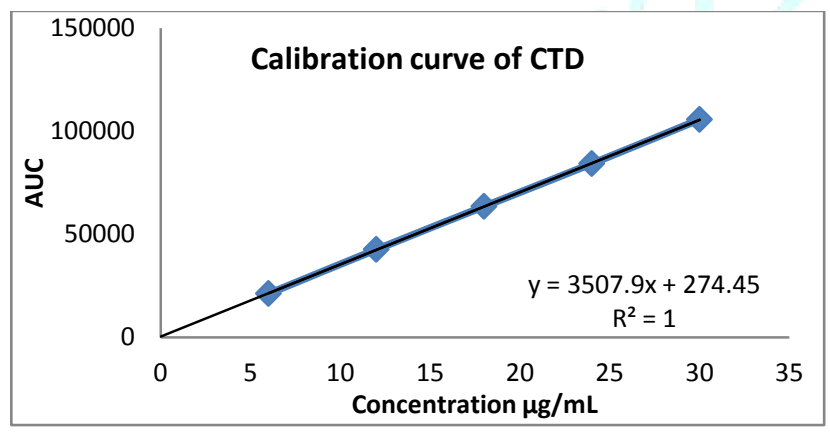

Figure 7: Calibration of CTD

\subsection{Accuracy}

The accuracy was assessed by the percent recovery method. According to the FDA guidelines, the mean value should be within $15 \%$ of the nominal value, except at LLOQ (Lower Limit of quantification), where it should not deviate by more than $20 \%$.

For CDP

$20 \mu \mathrm{g} / \mathrm{mL}$ drug solutions was taken in three different flask label A, B and C. Spiked 50\%, 100\%, 150\% of standard solution in it and diluted up to $10 \mathrm{ml}$. The area of each solution peak was measured at $225 \mathrm{~nm}$. The amount of CDP was calculated at each level and \% recoveries were calculated.

\section{For ATL}

$20 \mu \mathrm{g} / \mathrm{mL}$ drug solutions was taken in three different flask label A, B and C. Spiked 50\%, 100\%, 150\% of standard solution in it and diluted up to $10 \mathrm{ml}$. The area of each solution peak was measured at $225 \mathrm{~nm}$. The amount of ATL was calculated at each level and \% recoveries were calculated.

\section{For CTD}

$12 \mu \mathrm{g} / \mathrm{mL}$ drug solutions was taken in three different flask label A, B and C. Spiked 50\%, 100\%, 150\% of standard solution in it and diluted up to $10 \mathrm{ml}$. The area of each solution peak was measured at $225 \mathrm{~nm}$. The amount of CTD was calculated at each level and \% recoveries were calculated.

All the accuracy values were within $85-115 \%$ of the recovery range. Thus, our results suggested that the described method was accurate.

Table 6: Statistical data for accuracy

\begin{tabular}{|c|c|c|c|}
\hline Statistical data & CDP & ATL & CTD \\
\hline \% Mean & 99.31 & 98.26 & 98.00 \\
\hline SD & 0.310 & 1.023 & 0.800 \\
\hline \%R.S.D. & 0.312 & 1.041 & 0.817 \\
\hline
\end{tabular}

\subsection{Precision}

Repeatability (Intra-day precision) was studied by calculating the relative standard deviation (RSD) for nine replicates of mixture having the concentration of $10 \mu \mathrm{g} / \mathrm{mL}$ of CDP, $10 \mu \mathrm{g} / \mathrm{mL}$ of ATL , $10 \mu \mathrm{g} / \mathrm{mL}$ of CTD performed on the same day and under same experimental conditions. The relative standard deviations were calculated for results of determinations for each drugs. Inter-day precision studies include the estimation of variations in analysis when a method is used within laboratories, on different day. The SD \& RSD values obtained for intraday \& inter-day precision were summarised in the table.

Table 7: Statistical data for precision

\begin{tabular}{|l|c|c|c|c|c|c|}
\hline \multirow{2}{*}{ Statistical parameter } & \multicolumn{2}{|c|}{ CDP } & \multicolumn{2}{c|}{ ATL } & \multicolumn{2}{c|}{ CTD } \\
\cline { 2 - 7 } & $S D$ & $\% R S D$ & $S D$ & $\% R S D$ & $S D$ & $\% R S D$ \\
\hline Repeatability & 0.51 & 0.51 & 0.92 & 0.92 & 0.74 & 0.74 \\
\hline Intermediate Precision \\
\hline Day to day & 1.18 & 1.18 & 0.09 & 0.09 & 0.28 & 0.28 \\
\hline Analyst to Analyst & 0.73 & 0.73 & 0.92 & 0.92 & 1.28 & 1.29 \\
\hline
\end{tabular}




\subsection{Robustness}

As per International Conference of Harmonization norms, small, but deliberate variations in concentration of the mobile phase were made to test the method's capacity to remain unaffected. The ratio of mobile phase was Methanol: Water $(\mathrm{pH}$ 7) 80:20 v/v. Change in ratio of mobile phase from 78:22 to 82:18 and 80:20 for robustness.

Table 8: Robustness study of the proposed HPLC method

\begin{tabular}{|c|c|c|c|c|}
\hline \multirow{2}{*}{ Parameter } & \multirow{2}{*}{ Conditions } & \multicolumn{3}{|c|}{ Retention Time } \\
\cline { 2 - 5 } & & CDP & ATL & CTD \\
\hline \multirow{2}{*}{ Flow Rate (mL/min) } & 0.9 & $\mathbf{3 . 5 8}$ & 5.85 & 9.93 \\
\cline { 2 - 5 } & 1.0 & $\mathbf{3 . 2 5}$ & 5.36 & 9.02 \\
\cline { 2 - 5 } & 1.1 & $\mathbf{3 . 0 3}$ & 4.91 & 9.20 \\
\hline \multirow{2}{*}{ Mobile Ratio (v/v) } & $78: 22$ & $\mathbf{3 . 4 0}$ & 5.52 & 9.10 \\
\cline { 2 - 5 } & $80: 20$ & $\mathbf{3 . 2 5}$ & 5.36 & 9.02 \\
\cline { 2 - 5 } & $82: 18$ & $\mathbf{3 . 1 0}$ & 5.20 & 80 \\
\hline
\end{tabular}

\section{CONCLUSION}

The present RP-HPLC developed method for simultaneous evaluation CDP, ATL and CTD was validated as per ICH guideline. The developed RP-HPLC method was found to be simple, accurate, rapid selective and precise for the concurrent estimation of all three drugs. Hence, there is no biased result found by the validated method so method can be used for the routine analysis of these three drugs simultaneously or any combination of two drugs from these three drugs.

\section{REFERENCES}

1. Bharti Mittu A., \& Chauhan P. Analytical Method Development and Validation: A Concise Review. Journal of Analytical \& Bioanalytical Techniques, 2015;06(01). doi: 10.4172/21559872.1000233.

2. G.A.K. B., Prasad K. (2017). Development and Validation of Bioanalytical HPLC Method for Simultaneous Estimation of Cilnidipine \& Nebivolol in Human Plasma. International Journal of Pharmacy and Pharmaceutical Sciences, 9(10), p.253.

3. Fujii S, Kameyama K, Hosono M, Hayashi Y, Kitamura K: Effect of cilnidipine, a novel dihydropyridine Ca-channel antagonist, on N-type Ca channel in rat dorsal root ganglion neurons. J Pharmacol Exp Ther 1997; 280:1184 -1191.

4. Hirning LD, Fox AP, McCleskey EW, et al: Dominant role of Ntype $\mathrm{Ca} 2+$ channels in evoked release of norepinephrine from sympathetic neurons. Science 1988; 239:57-61.

5. Minami J, Ishimitsu T, Kawano Y, Numabe A, Matsuoka H: Comparison of 24-hour blood pressure, heart rate, and autonomic nerve activity in hypertensive patients treated with cilnidipine or nifedipine retard. J Cardiovasc Pharmacol 1998; 32:331 - 336.

6. Minami J, Ishimitsu T, Higashi T, Numabe A, Matsuoka H: Comparison between cilnidipine and nisoldipine with respect to effects on blood pressure and heart rate in hypertensive patients. Hypertens Res 1998; 21:215-219

7. Spanakis, M. and Niopas, I. Determination of Atenolol in Human Plasma by HPLC with Fluorescence Detection: Validation and Application in a Pharmacokinetic Study. Journal of Chromatographic Science, 2012; 51(2):128132.

8. Fitzgerald J.D., Ruffin R.,Smedstad K.G Roberts R., McAinsh J., Studies on the pharmacokinetics and pharmacodynamics of atenolol in man, European Journal of Clinical Pharmacology , 1978; 13:81-89)

9. Abdullah, N., Hassan, M. and Hassan, R. Spectrophotometric determination of chlorthalidone in pharmaceutical formulations using different order derivative methods. Arabian Journal of Chemistry, 2017; 10:S3426S3433.

10. Elgawish, M., Mostafa, S. and Elshanawane, A. Simple and rapid HPLC method for simultaneous determination of atenolol and chlorthalidone in spiked human plasma. Saudi Pharmaceutical Journal, 2011; 19(1):43-49.

11. ICH Proceedings of the International Conference on Harmonisation of Technical Requirement of Registration of Pharmaceuticals for Human Use (ICH Harmonised Tripartite Guidelines). Validation of Analytical Procedures: Methodology, Q2B.

12. Bishnoi RS, Kumar M, Shukla AK, Jain CP, Development and validation of novel HPLC method for the estimation of Rutin in crude hydromethanolic leaf extract of Prosopis cineraria, Journal of Drug Delivery and Therapeutics. 2018; 8(6):68-73 DOI: http://dx.doi.org/10.22270/jddt.v8i6.2016

13. Kumar M, Shukla AK, Bishnoi RS, Jain CP, Development of UV Spectrophotometric Method for The Determination of Benidipine Hydrochloride By Using Quality By Design (QbD) Approach. International Journal of Applied Pharmaceutics, 2018; 10(4):92-97. DOI: http://dx.doi.org/10.22159/ijap.2018v10i4.26623

14. Beludari M., Prakash K. and Mohan G. RP-HPLC method for simultaneous estimation of Rosuvastatin and Ezetimibe from their combination tablet dosage form. International Journal of Chemical and Analytical Science, 2013; 4(4):205-209.

15. Kim D., Yousaf A., Li D., Kim J., Yong C., Cho K. and Choi H. Development of RP-HPLC method for simultaneous determination of docetaxel and curcumin in rat plasma: Validation and stability. Asian Journal of Pharmaceutical Sciences, 2017; 12(1):105-113.

16. Kavathia A. and Misra M. Development and validation of RPHPLC and UV-spectrophotometric methods for rapid simultaneous estimation of amlodipine and benazepril in pure and fixed dose combination. Arabian Journal of Chemistry, 2017; 10:S3021-S3028.

17. Shabir GA. Validation of high-performance liquid chromatography methods for pharmaceutical analysis: understanding the differences and imilarities between validation requirements of the US Food and Drug Administration, the US Pharmacopeia and the International Conference on Harmonization. Journal of Chromatography $A$ 2003; 987(1):57-66. 